\title{
Efficacy and usability of a novel nebulizer targeting both upper and lower airways
}

\author{
Daniela Posa ${ }^{1}$, Antonio Pizzulli ${ }^{2}$, Petra Wagner ${ }^{1}$, Serena Perna ${ }^{1}$, Stephanie Hofmaier ${ }^{1}$, Paolo Maria Matricardi ${ }^{1}$
} and Susanne Lau ${ }^{1 *}$

\begin{abstract}
Background: Upper and lower airways diseases share in part their pathogenic mechanisms and frequently occur simultaneously as "United Airway Disease." Local treatment with nebulizers delivers anti-symptomatic drugs in either the upper or the lower airways, according to the particle size generated by the nebulizer. To our knowledge, no nebulizer combines both application ways.

The aim of this study is to test the efficacy and usability of a new nebulizer (OMRON A3 complete), generating aerosols with particles diameters of 2-4.5 $\mu \mathrm{m}, 4.5-7.5 \mu \mathrm{m}$ or $>7.5 \mu \mathrm{m}$, according to the user's choice.

Methods: Seventy-seven patients between 5 and 17 years of age with a diagnosis of rhinitis or asthma were examined. Oxymetazoline or Salbutamol were prescribed according to best clinical practice guidelines. Both drugs were administered through the OMRON A3 Complete nebulizer, with a particle dimension of $>7.5 \mu \mathrm{m}$ to treat nasal obstruction and 2-4.5 $\mu \mathrm{m}$ for bronchial obstruction. The efficacy of treatment was assessed by total nasal inspiratory airflow and FEV-1, Tiffeneau index (FEV1/FVC) and MMEF 25/75 respectively, 10 min before and after treatment. Symptom improvement and usability were measured by patients' and doctors' questionnaires.
\end{abstract}

Results: Overall, 77 patients seeking care for acute respiratory symptoms were assigned to the upper $(n=39)$ or lower ( $n=38$ ) airways disease group. For symptoms of the upper airways, $92 \%(95 \% \mathrm{Cl}, 77-97 \%)$ of the patients reported subjective improvement, while $87 \%(95 \% \mathrm{Cl}, 73-94 \%)$ did so for the lower airways. The average total nasal inspiratory airflow improved significantly ( $p=0.030$ ) among the patients with upper airways symptoms, from $275 \mathrm{ml} / \mathrm{s}(95 \% \mathrm{Cl}$, 207-342 ml/s) to $359 \mathrm{ml} / \mathrm{s}(95 \% \mathrm{Cl}, 300-419 \mathrm{ml} / \mathrm{s})$ after Oxymetazoline administration. All selected lung function parameters (FEV1, Tiffeneau Index and MMEF25-75) significantly improved among the patients with lower airways symptoms after inhalation of Salbutamol $(p<0.001)$. The nebulizer was assessed as "easy to use" by over $95 \%$ of participants in both groups.

Conclusions: The OMRON A3 efficiently delivers anti-symptomatic drugs in both upper and lower airways in a userfriendly way. This device may be useful to facilitate adherence to a complete treatment of respiratory symptoms in patients with symptoms of the so-called United Airway Disease.

Keywords: Asthma, Children, Nebulizer, Oxymetazoline, Rhinitis, Salbutamol

\footnotetext{
* Correspondence: Susanne.lau@charite.de

${ }^{1}$ Department of Paediatric Pneumology \& Immunology, Charité -

Universitätsmedizin, Augustenburger Platz, 1, 13353 Berlin, Germany

Full list of author information is available at the end of the article
} 


\section{Background}

Acute and chronic respiratory diseases in childhood are among the first causes of consultation in pediatrics and cause an enormous health and economic burden [1]. Upper (e.g. rhinitis, sinusitis) and lower (e.g. bronchitis, asthma) airways diseases share in part their pathogenic mechanisms and frequently occur simultaneously in the same patient [2-4]. Comorbidity of upper and lower airways has been also defined as "United Airway Disease" (UAD) [5].

To minimize systemic side effects, first-line treatment of airways inflammation is frequently based on local, rather than systemic drugs. Local treatments include corticosteroids and $\beta 2$-agonists for the lower airways, as well as corticosteroids, nasal anticholinergics and decongestants for the upper airways [2, 3]. Drugs can be administered with metered dose inhalers (MDI), nebulizers, or other devices [6]. The use of MDI is feasible but requires education, adherence and compliance of the patient, while nebulizers are suitable at any age as they do not require special skill in the inhalation technique [7].

Nebulizers are generally divided into two categories, according to the aerosol particle size they produce, i.e. 3-5 $\mu \mathrm{m}$ or $7.5-10 \mu \mathrm{m}$ to treat either the lower or the upper airways, respectively. Consequently, UAD patients needing local therapy for both upper and lower airways cannot receive their drugs with the same nebulizer.

The primary aim of this study is to test the efficacy of a new nebulizer (OMRON A3 complete) that can be switched to generate aerosols with different particle diameters: 2-4.5 $\mu \mathrm{m}, 4.5-7.5 \mu \mathrm{m}$ or $>7.5 \mu \mathrm{m}$. The secondary aim of the study is to evaluate whether the use of this new nebulizer is easy and well accepted by patients. To this end, we examined the efficacy and usability of $\mathrm{A} 3 \mathrm{C}$ in school children affected by acute exacerbation of asthma or rhinitis. We also assessed the subjective patients' and doctors' evaluation of symptoms improvement, acceptability, easiness, and comfort of the use of this new device.

\section{Methods}

\section{Study population and design}

The study population consisted of 77 patients between 5 and 17 years of age seeking care for rhinitis or asthma exacerbations in the Pediatric Outpatient Clinic of the Charité Universitätsmedizin Berlin or in one of its referring practices. The children were eligible for the upper airways study if they had: 1) a diagnosis of rhinitis with no contraindications to the use of local alpha adrenergic drugs; 2) a clear nasal blockage based on clinical assessment; 3) no remarkable anatomical reasons explaining nasal obstruction; 4) no intake of beta-blocker drugs. A 24-hourperiod free of alpha-adrenergic drugs was also required before testing. The children were eligible for the lower airways study if they had: 1) a diagnosis of asthma with no contraindications to the use of beta- 2 adrenergic drugs; 2) clinically assessed bronchial obstruction; 3) no remarkable anatomical reasons explaining bronchial obstruction or other severe chronic lung diseases; 4) no intake of beta-blocker drugs. A 12-h period free of long- (LABA) or short-acting $\beta$-adrenergic agonists was also required before testing. The study was approved by the local ethic committee. Participants and parents or legal tutors provided informed written consent at the time of enrollment.

\section{The nebulizer}

Drugs were administered through OMRON A3 Complete nebulizer (OMRON, Kyoto, Japan) (Fig. 1). This device produces aerosolized particles with different granulometric characteristics, whose dimensions are changed by switching a "Nebulization Control Ring" (NCR). The NCR in position 1, 2, or 3 produces particles of $>7.5 \mu \mathrm{m}, 4.5-7.5 \mu \mathrm{m}$ or 2$4.5 \mu \mathrm{m}$, respectively. In the present study, position 1 was selected to treat nasal obstruction and position 3 was used to treat bronchial obstruction. Further information on the $\mathrm{A} 3 \mathrm{C}$ nebulizer can be found at the following web address: https://www.omron-health care.com/en/support/manuals/search?utf8=\%E2\%9C\% 93\&q=NE-C300\&commit=\%EF\%84\%B4.

\section{Drug administration}

Children with nasal obstruction were treated with $120 \mu \mathrm{g}$ Oxymetazoline (6 drops of a solution at $0.05 \%)+2.5 \mathrm{ml} \mathrm{NaCl} 0.9 \%$ administered for 5 to $7 \mathrm{~min}$ with the $\mathrm{A} 3 \mathrm{C}$ nebulizer (NCR in position 1). Children with bronchial obstruction were treated with $1.25 \mathrm{mg}$ Salbutamol ( 5 drops of a solution at $5 \mathrm{mg} / \mathrm{ml})+2.5 \mathrm{ml}$ $\mathrm{NaCl} 0.9 \%$ administered for 8 to $10 \mathrm{~min}$ with the $\mathrm{A} 3 \mathrm{C}$ nebulizer (NCR in position 3 ).

\section{Endpoints}

The efficacy of the treatment with the A3C was measured at the individual level with questionnaires on the patients' and doctors' opinion on symptoms improvement. The efficacy of the drug delivery to the upper airways was defined at population level by the increase of the average total nasal inspiratory airflow (V'na) after administration of Oxymetazoline with the A3C (see below for details). V'na was measured according to standard procedures [8] with Rhinomanometry (ZAN 100, N-spire Health, Germany) $10 \mathrm{~min}$ before and after the treatment with Oxymetazoline. Participants were asked to blow their nose before starting the assessment and to breath normally with the mouth closed during the measurement. Subjects were invited to introduce in the nostrils the two plastic olives attached to flow and 

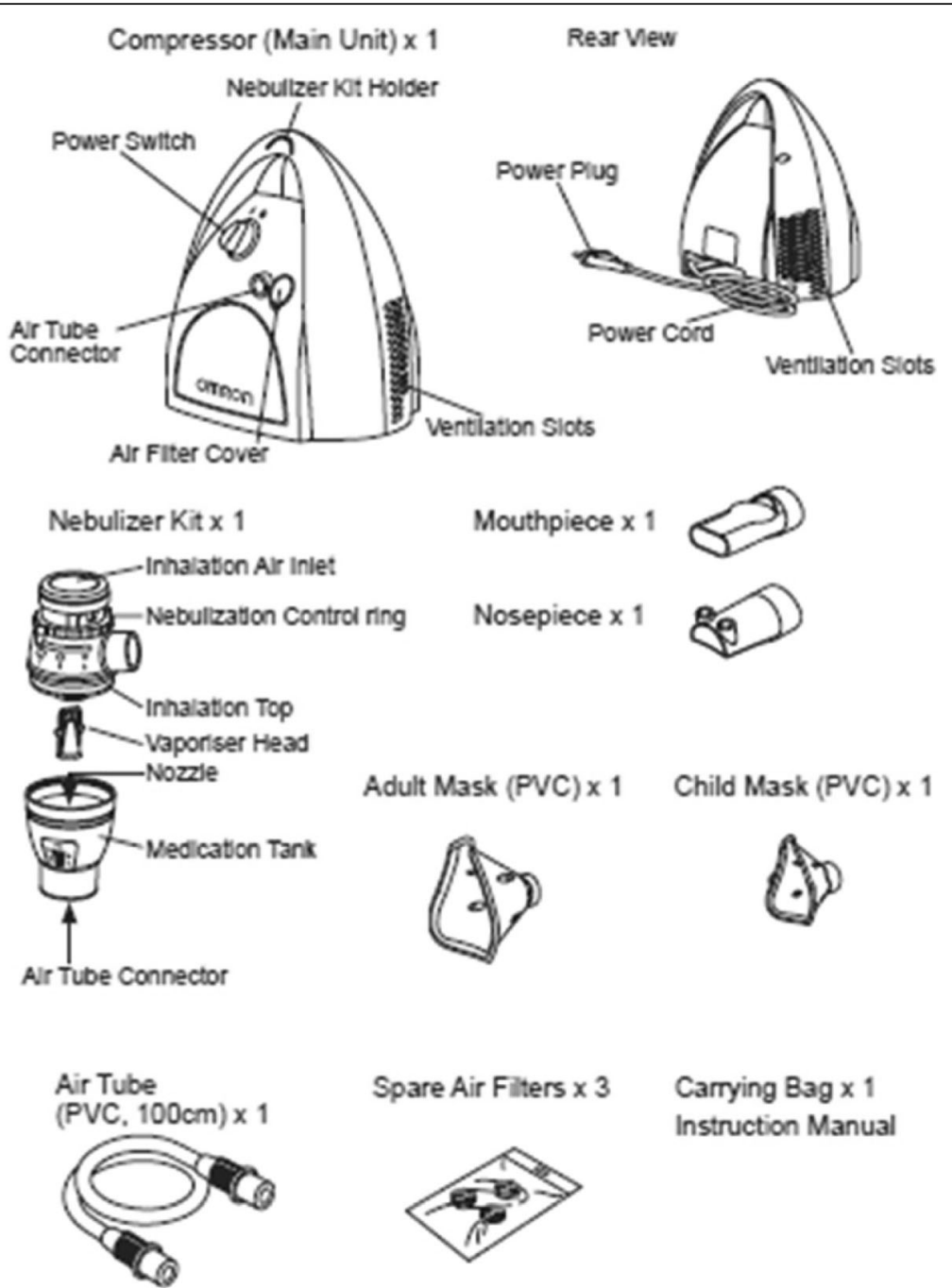

Fig. 1 Omron A3C nebulizer Instruction Manual

pressure sensors of the Rhinomanometry. Each nostril was evaluated separately [9].

The efficacy of drug delivery to the lower airways was defined at population level by the increase of FEV-1, Tiffeneau Index (FEV1/FVC) and Maximal Midexpiratory Flow (MMEF 25/75) after administration of Salbutamol with the A3C. These parameters were measured with a Spirometer (ZAN 100, N-spire Health, Germany) 15 min before and after the treatment with Salbutamol. The doctors' and patients' opinions on the acceptability, easiness, and comfort of the use of the $\mathrm{A} 3 \mathrm{C}$ were assessed through questionnaires. Patients were also asked to estimate their satisfaction of the use of the nebulizer through a Visual Analogue Scale (VAS).

\section{Statistical analysis}

Data were summarized as numbers ( $\mathrm{n}$ ) and frequencies (\%) if they were categorical and as mean and standard deviation (SD) if quantitative. To assess the normal distribution of quantitative data, the Shapiro-Wilk test was applied. A paired-samples t-test, when conditions were respected or Wilcoxon signed-rank test were performed to show differences in time within each group of patients. A $p$-value $<0.05$ was considered statistically significant. Statistical analyses were performed with $R$ statistical software (R Core Team, 2014), version 3.2.3.

\section{Results}

\section{Characteristics of the study population}

Overall 87 patients seeking care for acute respiratory symptoms were examined, of which 77 met the inclusion criteria to be assigned to the upper $(n=39)$ or to the lower $(n=38)$ airways disease group (Table 1$)$. Allergic rhinitis (33/39; 85\%) and allergic asthma (31/38; 82\%) were the most frequently diagnosed diseases in the group with upper and lower airways disease, respectively. 
Table 1 Characteristics of the study population and of the current disease exacerbation

\begin{tabular}{|c|c|c|c|c|}
\hline \multirow[b]{2}{*}{ Male gender, n (\%) } & \multicolumn{2}{|c|}{$\begin{array}{l}\text { rhinitis } \\
n=39\end{array}$} & \multicolumn{2}{|c|}{$\begin{array}{l}\text { asthma } \\
n=38\end{array}$} \\
\hline & 25 & 64 & 27 & 71 \\
\hline Age (yrs), mean (SD) & 9 & 3.0 & 10 & 3.0 \\
\hline Height (cm), mean (SD) & 139 & 17 & 143 & 18 \\
\hline Weight (kg), mean (SD) & 37 & 18 & 39 & 16 \\
\hline \multicolumn{5}{|l|}{ Atopic diseases, n (\%) } \\
\hline Allergic rhinitis & 33 & 85 & 21 & 55 \\
\hline Allergic asthma & 24 & 62 & 31 & 82 \\
\hline \multicolumn{5}{|l|}{ Etiology, n (\%) } \\
\hline Viral & 24 & 62 & 11 & 29 \\
\hline Bacterial & 1 & 3 & 1 & 3 \\
\hline Allergic & 27 & 69 & 26 & 68 \\
\hline Other & 4 & 10 & 8 & 21 \\
\hline \multicolumn{5}{|l|}{ Severity, n (\%) } \\
\hline low & 1 & 3 & 13 & 34 \\
\hline medium & 31 & 79 & 16 & 42 \\
\hline high & 4 & 10 & 7 & 18 \\
\hline very high & 3 & 8 & 2 & 5 \\
\hline \multicolumn{5}{|l|}{ Duration, n (\%) } \\
\hline 1-3 days & 4 & 10 & 21 & 55 \\
\hline 4-7 days & 12 & 31 & 6 & 16 \\
\hline 7-15 days & 11 & 28 & 8 & 21 \\
\hline$>15$ days & 12 & 31 & 3 & 8 \\
\hline Impaiment of sleeping, n (\%) & 18 & 46 & 13 & 34 \\
\hline Impairment of eating, n (\%) & 0 & 0 & 3 & 8 \\
\hline
\end{tabular}

Data were summarized as numbers ( $\mathrm{n}$ ) and frequencies (\%) if they were categorical and or mean and standard deviation (SD) if quantitative

${ }^{a}$ More than one etiology is possible in the same subject

An allergic reaction or a viral infection were the most common triggers of the acute exacerbation to be treated. The severity of symptoms to be treated was classified as "moderate" by the patients in $79 \%$ and $42 \%$ of those having upper or lower airways symptoms, respectively. Symptoms were more frequently short lived (1-3 days) in the group with lower airways disease than in that with upper airways disease $(55 \%$ vs $10 \%, p<0.001)$, but the latter suffered more frequently from sleep impairment (46\% vs $34 \%, p=0.285$ ) (Table 1 ).

\section{Efficacy}

The percentage of patients reporting a subjective feeling of clear symptoms improvement was 92\% (95\% CI, 77-97\%) and $87 \%$ (95\% CI, 73-94\%) in the upper and lower airways disease groups, respectively (Fig. 2). Doctors judged a clear improvement of symptoms in 90\% (95\% CI, 76-96\%) and 97\% (95\% CI $87-100 \%)$ of the patients with upper and lower airways disease, respectively (Fig. 2).

The average total nasal inspiratory airflow significantly improved $(p=0.030)$ among the patients with upper airways symptoms, from $275 \mathrm{ml} / \mathrm{s}(95 \% \mathrm{CI}, 207-342 \mathrm{ml} / \mathrm{s})$ to $359 \mathrm{ml} / \mathrm{s}(95 \% \mathrm{CI}, 300-419 \mathrm{ml} / \mathrm{s})$ after Oxymetazoline administration with the A3C nebulizer (Table 2). The frequency distributions of V'na values measured before and after nebulization were notably different. Particularly, V'na values evaluated after nebulization were distributed towards higher values, with a peak in interval between 51 and 75 V'na (\%). Moreover, the mean differences resulted statistically significant ( $44 \%$ vs $61 \%, p=0.010$ ) (Fig. 3a).

All the selected lung function parameters (FEV1, Tiffeneau Index and MMEF25-75) significantly improved among the patients with lower airways symptoms after inhalation of Salbutamol (Table 2). Similarly, MMEF 25/75 values measured after nebulization revealed a tendency towards higher values, with a peak in the interval between 61 and 80 MMEF 25/75 (\%).The mean pre-post nebulization differences were statistically significant (51\% vs $77 \%, p<0.001)$ (Fig. $3 \mathrm{~b})$.

\section{Usability}

Only $1 / 39$ patients with upper airway disease (3\%) and 2/38 patients with lower airway disease (5\%) reported a previous use of the $\mathrm{A} 3 \mathrm{C}$ nebulizer. The nebulizer was assessed as "easy to use" by $97 \%$ of the participants in both groups (Fig. 2a). 85\% and over 92\% of the participants with disease of the upper or lower airways, respectively, expressed the wish to use the nebulizer again. More than $85 \%$ of the patients affected by UAD considered the possibility of using one single nebulizer to treat their symptoms of both upper and lower airways as useful. Overall, only seven patients evaluated the use of the nebulizer as "uneasy" (Fig. 2a). Doctors did not indicate any problem in the patients' use of the device for both groups and would have prescribed the use of the nebulizer for over $90 \%$ of their patients again (Fig. 2b).

\section{Discussion}

\section{What we found}

We tested the efficacy and usability of a novel nebulizer (A3 complete, OMRON, Kyoto, Japan) in two groups of children with either upper or lower airways disease. In both groups the nebulizer was considered as "easy to use" by the patients. The successful delivery of the anti-symptomatic drug (Oxymetazoline or Salbutamol) was assessed at individual level through the subjective opinion of the patients and their doctor. At population level, the success of drug delivery in the target tissue was measured by the improvement of objective upper or lower airways parameters, i.e. total inspiratory nasal airflow and 


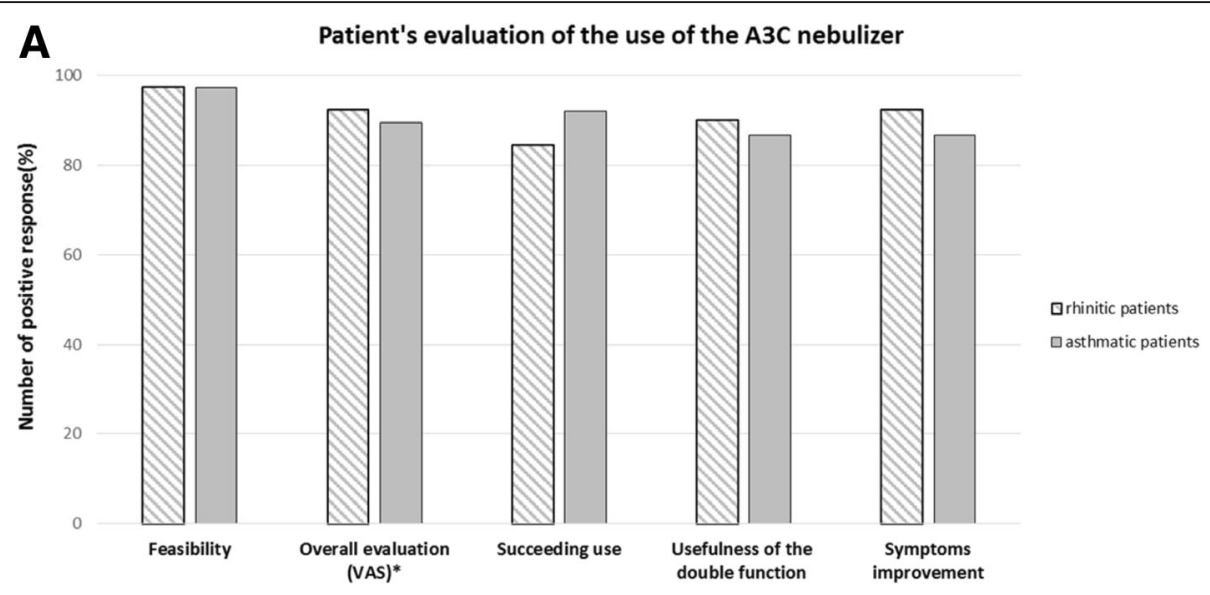

B Doctor's evaluation of the use of the $A 3 C$ nebulizer

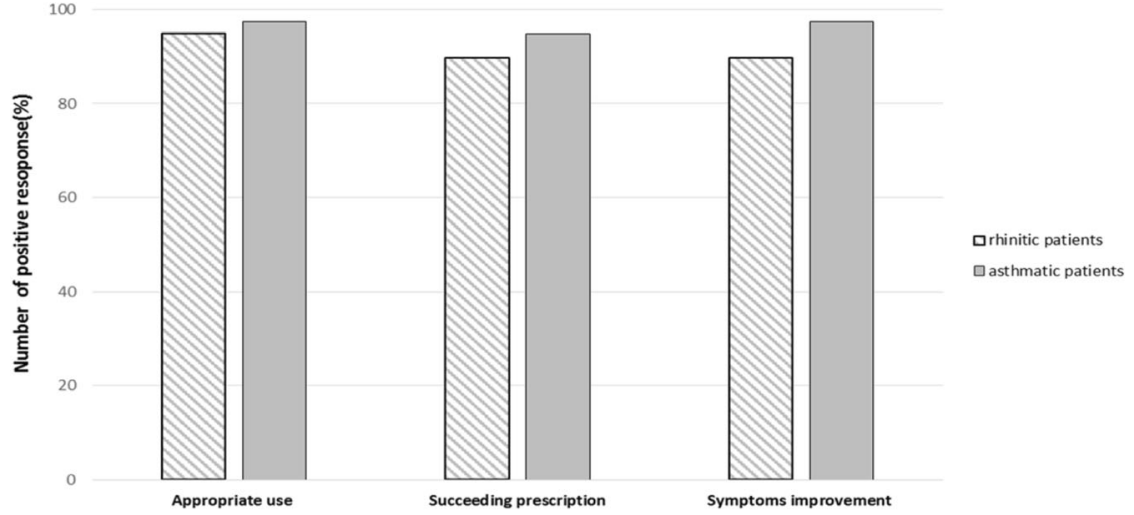

Fig. 2 Subjective evaluation (a) Subjective patient's evaluation of the use of the A3C nebulizer in 39 rhinitic patients and in 38 asthmatic patients. A response between 1 and 4 in a Visual Analogue Scale from 1 to 10 was considered as positive. $\mathbf{b}$ Doctor's evaluation of the use of the A3C nebulizer in 39 rhinitic patients and in 38 asthmatic patients

lung function parameters. (FEV1, Tiffeneau Index, MMEF 25/75) To our knowledge, this is the first example of a nebulizer being able to effectively deliver drugs to both the upper and lower airways; actually, no nebulizer with this property has been mentioned in a recent, comprehensive review on nebulizers [10].

\section{Drug deposition in upper/lower airways}

The efficacy of drug delivery in the lower airways was clearly detected at population level in terms of variation of FEV-1. This increase was remarkably evident when the Maximal Midexpiratory Flow (MMEF25-75) was taken into account. This suggests a successful penetration and

Table 2 Quantitative improvement of respiratory parameters in 39 rhinitic patients and in 38 asthmatic patient after drug administration with $\mathrm{A} 3 \mathrm{C}$ nebulizer

\begin{tabular}{|c|c|c|c|c|c|}
\hline & \multicolumn{2}{|c|}{ pre } & \multicolumn{2}{|c|}{ post } & \multirow[t]{2}{*}{$p$-value ${ }^{a}$} \\
\hline & mean & SD & mean & SD & \\
\hline \multicolumn{6}{|l|}{ Rhinitic patients } \\
\hline Total nasal inspiratory airflow (ml/s) & 275 & 216 & 359 & 188 & 0.030 \\
\hline \multicolumn{6}{|l|}{ Asthmatic patients } \\
\hline FEV 1 (I) & 1.59 & 0.63 & 1.90 & 0.80 & $<0.001$ \\
\hline Tiffeneau index (\%) & 78 & 11.0 & 87 & 10.1 & $<0.001$ \\
\hline MMEF 25-75 (I/s) & 1.32 & 0.50 & 2.01 & 0.85 & $<0.001$ \\
\hline
\end{tabular}

Quantitative data were summarized as mean and standard deviation (SD)

${ }^{a} \mathrm{~A}$ paired t-test, when condition were respected (Shapiro-Wilk test was used to assess normality of data), or Wilcoxon signed-rank test was performed to show differences in time within each group 

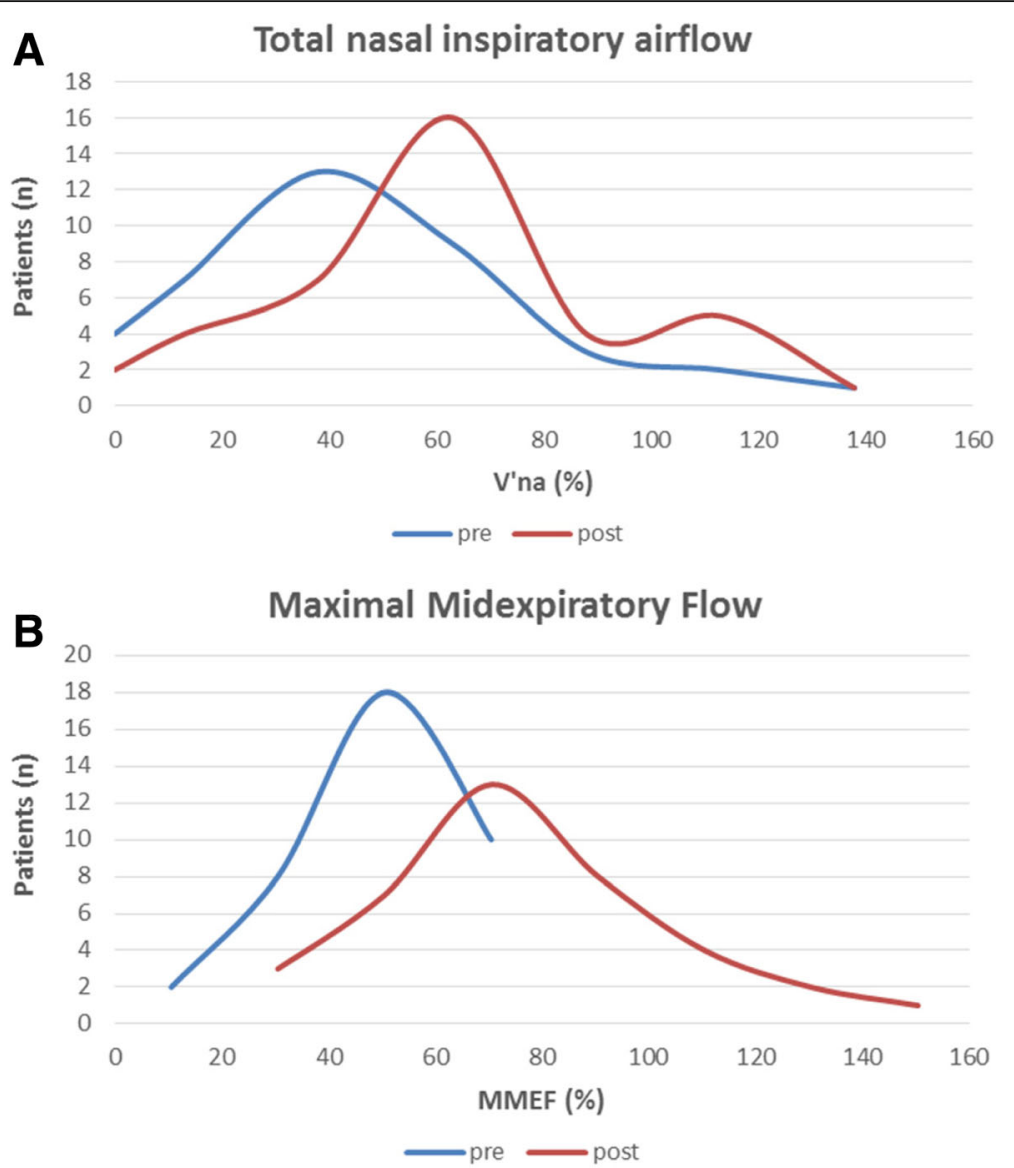

Fig. 3 Objective evaluation of (a) quantitative improvement of the Total Nasal Inspiratory Airflow at population level and (b) quantitative improvement of the Maximal Midexpiratory Flow at population level. a Smoothed frequency distribution of V'na values (expressed as percentage (\%) of the expected value) measured before (pre) and after (post) nebulization. b Smoothed frequency distribution of MMEF 25/75 values (considered as percentage (\%) of the expected values) measured before (pre) and after (post) nebulization

deposition of the drug (Salbutamol) in the targeted segment of the airways, i.e. the medium-size and smaller bronchi. Accordingly, this improvement was also accompanied by a clear improvement of the Tiffeneau Index. Most of the patients subjectively reported improvement of their bronchial symptoms, assessed both through specific questioning (87\%) and a visual analogue scale (89\%). The efficacy of drug delivery in the upper airways was detected at population level by measuring the total nasal inspiratory flow. This objective improvement suggests the effective penetration and deposition of the drug (Oxymetazoline) in the upper airways. Accordingly, most patients subjectively reported improvement of their nasal symptoms.

\section{Usability of the device for patients with UAD}

The improvement of subjective and objective symptoms reflects why patients and doctors consider the use of the nebulizer successful. Interestingly, the patients with symptoms in both upper and lower airways expressed appreciation for the possibility of treating both affected sites with a unique nebulizer. Additionally, the instrument seemed to be user-friendly for most of the participating patients. In certain patients (e.g. pre-school children, patients with difficult coordination or low attention) the use of a single and easier device, which is able to treat both the upper and lower airways, may be preferable and facilitate adherence to a complete treatment of the so-called "United Airways Disease" [11, 12].

\section{Choosing the appropriate device for each patient}

Although the use of the $\mathrm{A} 3 \mathrm{C}$ has been shown to be beneficial for patients with rhinitis and asthma, one should consider that nebulizers generally are not the most frequently used drug delivery devices in the treatment of both pathologies [13]. In particular, the European and German national guidelines for the treatment of rhinitis and asthma suggest as first choice the use of nasal drops/sprays and metered dose inhalers 
with aero-chamber to deliver anti-symptomatic drugs or corticosteroids in the upper and lower airways, respectively $[14,15]$.

One of the reasons for this recommendation is that most nebulizers are relatively big, not easily carried instruments, requiring electric power [16]. This impedes an outdoor use, e.g. during sports or at school [17], which is an essential limiting factor with regard to the treatment of acute disease exacerbations, especially in asthma. Moreover, some nebulizers have a relatively high degree of variability in their efficiency of drug delivery over time [18].

\section{Study limitations}

We have to acknowledge some limitations of our study. First, we did not compare the efficacy of A3C with that of other nebulizers. Nevertheless, the very high efficacy measured suggests non-inferiority to other nebulizers already available on the European market in delivering drugs to either upper or lower airways. Second, we measured the impact of therapy only in not-hospitalized patients affected by milder forms of acute exacerbations of respiratory diseases. We stress that our conclusions cannot be automatically extrapolated, without further studies, to more severe conditions, such as severe asthma, cystic fibrosis or to use in unconscious patients. Third, the subjective opinion of patients and doctors and the objective measures of lung or nasal function were based on one episodic treatment only, without further follow-up assessments. A study evaluating the efficacy of the instrument on patients monitored longterm would have been more informative.

\section{Conclusions}

In conclusion, this study has shown that the A3C nebulizer efficiently delivers anti-symptomatic drugs in both the upper and lower airways in a userfriendly way. This device may be useful to facilitate adherence to a complete treatment of respiratory symptoms in patients with symptoms of both upper and lower airways symptoms, i.e. the so-called United Airways Disease.

\section{Abbreviations}

A3C: OMRON A3 complete nebulizer; Cl: Confidence interval; FEV1: Forced expiratory volume in $1 \mathrm{~s}$; FVC: Forced vital capacity; MDI: Metered dose inhalers; MMEF 25/75: Maximal midexpiratory flow; NCR: Nebulization control ring; SD: Standard deviation; UAD: United airway disease; V'na: Total nasal inspiratory airflow; VAS: Visual analogue scale

\section{Acknowledgements}

We are indebted to Holger Röblitz, Katharin Volk, Antje Pizzulli and all the nurses in their practices for their contribution to the study. We also thank Bodo Niggemann and all doctors and nurses of the Outpatient Clinic of the Paediatric Pneumology \& Immunology, Charité - Universitätsmedizin Berlin for the collaboration in the recruitment. Furthermore, we acknowledge all the families participating. We thank Charles Clawson for English editing.

\section{Funding}

This study was supported by an unrestricted grant from OMRON (KS89772242). The funders had no role in the design, management, data collection, analysis or interpretation of the data or in the writing of the manuscript or the decision to submit for publication.

\section{Availability of data and materials}

The datasets used and/or analyzed during the current study are available from the corresponding author on reasonable request.

\section{Authors' contributions}

DP participated in the design of the study, performed data management and drafted the manuscript. AP and PW carried out clinical data collection. SP performed statistical analysis. SH contributed to draft the manuscript. PMM designed the study, monitored data management and contributed to draft the manuscript. SL designed the study, performed and coordinated clinical data collection, and revised the manuscript. All authors read and approved the final manuscript.

Ethics approval and consent to participate

The study was approved by the Charité Ethic Committee. The informed consent was obtained from participants and their parents after full explanation of the purpose and nature of all procedures used.

\section{Consent for publication}

The patients and their parents released their consent for the publication of their data in an anonymous form.

\section{Competing interests}

SL receives grant support from German Ministry of Agriculture and Nutrition, Symbiopharm and Merck and personal fees from Merck. PMM serves as a consultant for Thermo Fisher Scientific, HYCOR biomedical, and Euroimmun AG, receives grant support from Thermo Fisher Scientific, and receives lecture fees from OMRON. The other authors declare that they have no relevant conflicts of interests.

\section{Publisher's Note}

Springer Nature remains neutral with regard to jurisdictional claims in published maps and institutional affiliations.

\section{Author details}

${ }^{1}$ Department of Paediatric Pneumology \& Immunology, Charité Universitätsmedizin, Augustenburger Platz, 1, 13353 Berlin, Germany.

${ }^{2}$ Practice for Pediatric Allergy and Pneumology, Berlin, Germany.

Received: 1 June 2017 Accepted: 10 September 2017

Published online: 29 September 2017

\section{References}

1. Ellwood P, Asher MI, Billo NE, Bissell K, Chiang CY, Ellwood EM, et al. The Global Asthma Network rationale and methods for Phase I global surveillance: prevalence, severity, management and risk factors. Eur Respir J. 2017:49(1).

2. Roberts G, Xatzipsalti M, Borrego LM, Custovic A, Halken S, Hellings PW, et al. Paediatric rhinitis: position paper of the European Academy of Allergy and Clinical Immunology. Allergy. 2013;68(9):1102-16.

3. Reddel HK, Bateman ED, Becker A, Boulet LP, Cruz AA, Drazen JM, et al. A summary of the new GINA strategy: a roadmap to asthma control. Eur Respir J. 2015;46(3):622-39.

4. Jarvis D, Newson R, Lotvall J, Hastan D, Tomassen P, Keil T, et al. Asthma in adults and its association with chronic rhinosinusitis: the GA2LEN survey in Europe. Allergy. 2012;67(1):91-8.

5. Passalacqua G, Ciprandi G, Canonica GW. The nose-lung interaction in allergic rhinitis and asthma: united airways disease. Curr Opin Allergy Clin Immunol. 2001;1(1):7-13.

6. Pirozynski M, Sosnowski TR. Inhalation devices: from basic science to practical use, innovative vs generic products. Expert Opin. Drug Deliv. 2016;13(11):1559-71.

7. Nelson HS. Inhalation devices, delivery systems, and patient technique. Ann Allergy Asthma Immunol. 2016;117(6):606-12. 
8. Clement PA, Gordts F. Standardisation Committee on Objective Assessment of the Nasal Airway IRS, Ers. Consensus report on acoustic rhinometry and rhinomanometry. Rhinology. 2005;43(3):169-79.

9. Zapletal A, Chalupova J. Nasal airflow and resistance measured by active anterior rhinomanometry in healthy children and adolescents. Pediatr Pulmonol. 2002;33(3):174-80.

10. Carvalho TC, McConville JT. The function and performance of aqueous aerosol devices for inhalation therapy. J Pharm Pharmacol. 2016;68(5):556-78.

11. Compalati E, Ridolo E, Passalacqua G, Braido F, Villa E, Canonica GW. The link between allergic rhinitis and asthma: the united airways disease. Expert Rev Clin Immunol. 2010;6(3):413-23.

12. Passalacqua G, Ciprandi G, Canonica GW. United airways disease: therapeutic aspects. Thorax. 2000;55(Suppl 2):S26-7.

13. Scichilone N, Benfante A, Bocchino M, Braido F, Paggiaro P, Papi A, et al. Which factors affect the choice of the inhaler in chronic obstructive respiratory diseases? Pulm Pharmacol Ther. 2015;31:63-7.

14. Fokkens W, Lund V, Bachert C, Clement $P$, Hellings $P$, Holmstrom $M$, et al. EAACl position paper on rhinosinusitis and nasal polyps executive summary. Allergy. 2005;60(5):583-601.

15. D. Berdel JF, Gappa M, Kiosz D, Leupold W, Pfeiffer-Kascha D, Rietschel E, Schuster A, Sitter H, Spindler T, Wahlen. Asthma bronchiale im Kindes- und Jugendalter S2-Leitlinie der Gesellschaft für Pädiatrische Pneumologie (GPP), der Gesellschaft für Pädiatrische Allergologie und Umweltmedizin (GPA), der Arbeitsgemeinschaft Asthmaschulung im Kindes- und Jugendalter (AGAS) und der Gesellschaft für Pädiatrische Rehabilitation. Leitlinien der Gesellschaft für Pädiatrische Allergologie und Umweltmedizin eV ICD-10Nummer: J45.9; J45.0, J45.1, J45.8. 2006.

16. DiBlasi RM. Clinical Controversies in Aerosol Therapy for Infants and Children. Resp Care. 2015;60(6):894-914.

17. Dolovich MB, Dhand R. Aerosol drug delivery: developments in device design and clinical use. Lancet. 2011;377(9770):1032-45.

18. Boe J, Dennis JH, O'Driscoll BR, Bauer TT, Carone M, Dautzenberg B, et al. European Respiratory Society Guidelines on the use of nebulizers. Eur Respir J. $2001 ; 18(1): 228-42$

\section{Submit your next manuscript to BioMed Central and we will help you at every step:}

- We accept pre-submission inquiries

- Our selector tool helps you to find the most relevant journal

- We provide round the clock customer support

- Convenient online submission

- Thorough peer review

- Inclusion in PubMed and all major indexing services

- Maximum visibility for your research

Submit your manuscript at www biomedcentral.com/submit 